\title{
Unusual yeasts isolated from immunocompromised patients
}

\author{
Zahraa S Kasim*, Manahil M Yehia** \\ *Department of Clinical Pharmacy, College of Pharmacy, **Department of Microbiology, College of Medicine,
} University of Mosul, Iraq.

$$
\frac{\text { Received }}{Y .1 \cdot Y \cdot \mid 1} \quad \frac{\text { Accepted }}{|Y .| Y . Y \cdot 11}
$$

ABSTRACT

Objectives: To identify rare fungi from saliva and urine of immunocompromised patients, and apparently healthy controls and to test the susceptibility of the rare fungi to antifungal agents.

Patients and methods: One hundred and twenty immunocompromised (cancer, diabetic) patients were enrolled in this study. The clinical specimens were collected from January-July $r \cdot 1 l$ and included saliva $(Y \cdot \cdot)$ and urine ( $r \cdot$ ) samples, in addition to saliva $\left({ }^{\cdot} \cdot\right.$ ) and urine $\left({ }^{\cdot}\right)$ samples from a control group. The identification process employed direct examination, culture, biochemical tests and API- $r \cdot C$ system test. Susceptibility test to six antifungal agents was prepared for each isolate.

Results: Among 11 . yeast isolates, only $\vee(7 . r \%)$ were categorized as unusual yeasts belonging to three genera. Four isolates were Cryptococcus laurantii, one C.neoformans, one Saccharomyces cereviciae, and one isolate was Rhodotorula rubra. All the isolates have various susceptibility to antifungal agents.

Conclusion: Many opportunistic fungi are important uncommon pathogens in saliva and urine of immunocompromised patients.

الخلاصة

الأهداف: تمييز الفطريات النادرة من اللعـاب و البول لمرضسى ذوي المناعة المنقوصـة و من أفراد أصحاء

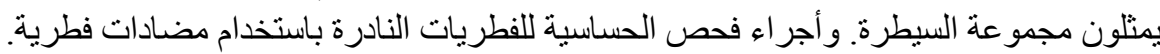

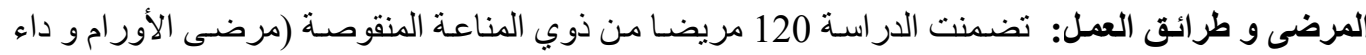

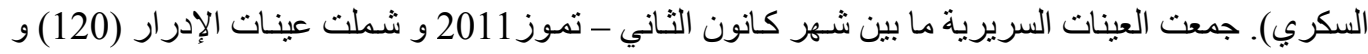

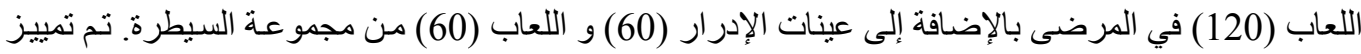

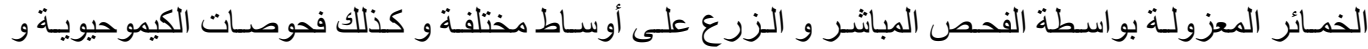

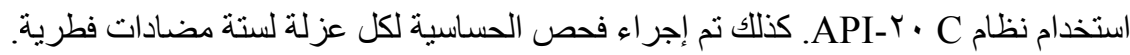

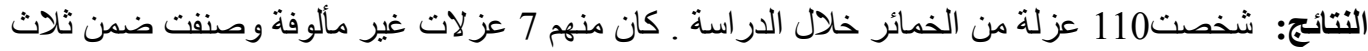

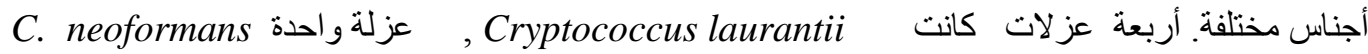

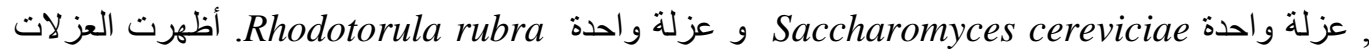
حساسيات مختلفة للمضادات الفطرية. الاستتناج: تعد بعض من الفطريات الانتهازية من الممرضات المهمة غير الثنائعة في لعاب و بول المرضى ذوي المناعة المنقوصة.

$\prod$ he medical advance has improved therapeutic capabilities for a variety of diseases. However, certain therapies like the cytotoxic and others that lead to immunosuppression may predispose the host to an expanding group of opportunistic pathogens'. The increasing population of immunocompromised patients has led 
to infections with less common organisms ${ }^{r}$. On the other hand, the severely immunosuppressed patients have a state in which the immune system is suppressed by medications during the treatment of cancer or other disorders as chronic renal failure and diabetes $^{r, \varepsilon}$.

Most fungal infections are caused by common opportunistic fungi as Candida species and Aspergillus spp. . A number of non-Candida yeast like fungi found an opportunity to colonize and infect immunocompromised patients. These organisms may occupy environmental niches or be found in food and water and can be normal human microbial flora'. The list of these opportunistic yeasts is long, but the main pathogen is Cryptococcus spp., in addition to Rhodotorula spp., Malassezia spp., and Saccharomyces spp., which emerging as significant causes of infection in immunocompromised patients $, 7, \frac{Y}{}$.

The techniques of antifungal susceptibility test have now been standardized, and in vitro antifungal susceptibility test results of the drug tested can be used to predict in vivo clinical response'. The recognition of unusual yeasts as agents of sometime life-threatening infections and their unpredictable antifungal susceptibility increase the burden on the clinical microbiology laboratory to complete species identification and determine minimal inhibitory (MIC) concentration ${ }^{\wedge}$. The aim of the study is to detect rare fungi from saliva and urine of immunocompromised (cancer and diabetic) patients, and to test their susceptibility to antifungal agents.

\section{Materials and methods}

One hundred and twenty immunocompromised patients were included in this study. The males were os $(\{0 \%)$ and females were $77(00 \%)$. The age of the patients ranged from ' $\wedge$. (mean \pm SD: $01 . \leqslant \Lambda \pm 17 . \leqslant r)$ years. The immunocompromised patients were: $7 \cdot(0 . \%)$ diabetic patients with uncontrolled diabetes mellitus of $>0$ years duration. and their fasting blood sugar more than ${ } \cdots \mathrm{mg} / \mathrm{dL}$ and $r$. $(0 . \%)$ patients with different types of cancer, and under treatment with chemotherapy.

Sixty apparently healthy individuals were included in the present study as a control group. They were $T V(\$ 0 \%)$ males and $r$ r (00\%) females. Their ages ranged between 1A. (mean \pm SD: $0 ., 1 \mathrm{r} \pm 10 . \mathrm{r} 4)$ years. These individuals were sex and age matches with the immunocompromised patients.

A total of $r \leqslant$. samples were collected from patients in Alwafa'a Center for diabetes, Center of Outpatients of Oncology and Nuclear Medicine Hospital, and Center of Outpatients in Ibn-Sina Teaching Hospital. The samples were consisted of $T$. saliva and $T$. urine samples. From the 7 . control individuals, both saliva and urine samples were also collected and processed in the same manner as for the patients.

Early morning saliva samples were collected from all patients in dry sterile wide mouth containers ${ }^{9}$. The samples brought to the laboratory within one hour after collection. The mid stream urine in the early morning was collected from each patient after cleaning the genital area into dry sterile 
plastic wide mouth container. The specimens were transferred to the laboratory without any delay ${ }^{\circ}$.

The saliva samples were used directly for culture and direct microscopical examination. Urine samples were centrifuged for $r$ minutes at 10. rpm. The supernatant was discarded, and the sediment was used for culture and direct microscopical examination.

\section{Isolation of the yeasts}

A loopful $(\cdot .1 \mathrm{ml})$ of the clinical specimen (saliva and urine) was inoculated onto each of Sabouraud's agar and Brain-Heart Infusion (BHI) blood agar. The specimens were streaked on all the surfaces of the media to obtain separated colonies. The plates then incubated aerobically at ${ }^{r} v{ }^{\circ} \mathrm{C}$ for $r_{-} r$ days. The cultures were examined after the second day of incubation and considered negative after the third day, then discarded after five days if no growth was obtained'.

\section{Direct examination}

Two smears were prepared from each clinical specimen. Wet mounted slide with a drop of calcoflour solution and a drop of $r . \% \mathrm{KOH}$ solution with glycerin, then examined under $\varepsilon \cdot X$ fluorescent microscope ${ }^{\gamma}$. The second heat fixed smear was stained by Gram's method and examined under oil immersion lens.

\section{Identification of the isolates} Lactophenol mount, biochemical tests (API-Y., urease), germ tube test, morphology on cornmeal agar Tween $\wedge \cdot$, and capsule stain were used for identification of the yeast species '.

\section{Antifungal susceptibility test}

The standard disk diffusion method was used to determine the sensitivity of the uncommon yeast against different antifungal agents (nystatin $0 . \mu \mathrm{g}$, amphotericin B $r \cdot \mu \mathrm{g}$, fluconazole $r_{0}$ $\mu \mathrm{g}$, voriconazole ' $\mu \mathrm{g}$, itraconazole 1 . $\mu \mathrm{g}$ and Ketoconazole $10 \mu \mathrm{g}$ ) according to Vale-Silva and Buchta"'.

A suspension of the tested yeast compared to $\cdot{ }^{\circ}$ McFarland scale was prepared in a test tube. A sterile cotton swab soaked in yeast suspension was used to inoculate the organism onto the surface of Muller-Hinton agar plates. The plates were left at room temperature for several minutes in order to dry, then the antifungal disks were placed firmly on the surface of the inoculated plates using a sterile forceps. The plates were incubated for $r \varepsilon_{-} \varepsilon \wedge$ hours at $r \vee{ }^{\circ} \mathrm{C}$.

\section{Results}

Three genera of unusual yeasts were identified in seven ( $7 . r \%$ ) out of 11 . yeast isolates from $1 \mathrm{r}$. cancer and diabetic patients from both saliva and urine. No isolates of the opportunistic unusual yeasts were identified from the control group (Table').

Five isolates of genus Cryptococcus were detected from saliva and urine of the patients. One isolate from saliva of cancer patient identified as C. neoformans. The other $\varepsilon$ isolates were identified as $C$. laurantii, $r$ of them detected in saliva of cancer patients, one from urine of the same group of patients, While the fifth isolate from saliva of diabetic patient (Table r). Different tests were used to identify the 0 isolates. These were direct examination of the clinical specimens with different stains 
including capsule stain, and culture on two types of media (Fig 1-A,B). Additional identification tests namely urease test and API- $r \cdot C$ system which identify the species of each isolate.

One isolate of the genus Saccharomyces was detected from the saliva of cancer patient (Table r). This isolate grew well on Sabouraud's agar with dry white colonies and microscopically showed budding yeast cells with fragments of mycelial elements (Fig)-C,D), and then identified as $S$. cereviciae by API- $r$. C system.

Rhodotorula was detected in saliva of one cancer patient. Showing pink mucoid colony on Sabouraud's agar and large budding yeast cells in lactophenol mount (Fig)-E,F). The isolate gave positive urease test and identified as $R$. rubra (mucilaginosa) by API- $r$. C system.

\section{Sensitivity test}

The results of the sensitivity tests with the six antifungal agents used are shown in Table r. The one isolate of C.neoformans from saliva of cancer patient showed sensitivity to nystatin, fluconazole and itraconazole only. On the other hand, the $r$ isolates of $C$. laurantii from saliva of the patients were sensitive to ketoconazole and resist to itraconazole. Two isolates sensitive to Polyenes and voriconazole, and one sensitive to fluconazole. The one isolate of $C$. laurantii obtained from urine was sensitive only to amphotericin B and ketoconazole, and the sensitivity to nystatin was excluded. Saccharomyces cereviciae showed sensitivity to polyenes and azole compound except itraconazole. Lastly, R.rubra was sensitive only to ketoconazole and voriconazole.

Table '. Number and percentage of Candida species and unusual yeasts isolated from the studied subjects.

\begin{tabular}{|c|c|c|c|c|c|c|}
\hline \multirow{2}{*}{ Studied subjects } & \multicolumn{2}{|c|}{ Total isolates } & \multicolumn{2}{|c|}{ Candida species } & \multicolumn{2}{|c|}{$\begin{array}{c}\text { Unusual yeast } \\
\text { species }\end{array}$} \\
\hline & No. & $\%$ & No. & $\%$ & No. & $\%$ \\
\hline Cancer patients & 07 & 0.9 & 0. & $\leqslant 0.0$ & 7 & $0 .\{$ \\
\hline Diabetic patients & $0 \varepsilon$ & $\leq 9.1$ & or & $\leq \Lambda . r$ & 1 & .9 \\
\hline Total & 11. & $1 \ldots$ & $1 . r$ & qт. & v & 7. \\
\hline Control group & 11 & $1 \ldots$ & 11 & $1 \ldots$ & - & - \\
\hline
\end{tabular}

Number of specimens with $r$ species $=\varepsilon$

Isolates from saliva and urine at the same time obtained from 17 patients. 
Table $r$. Number and percentage of unusual yeast species isolated from saliva and urine of the immunocompromised (cancer, diabetic) patients.

\begin{tabular}{|c|c|c|c|c|c|c|c|c|c|c|}
\hline \multirow{3}{*}{ Isolate species } & \multirow{2}{*}{\multicolumn{2}{|c|}{$\begin{array}{c}\text { Total } \\
\text { isolates }\end{array}$}} & \multicolumn{4}{|c|}{ Cancer patients } & \multicolumn{4}{|c|}{ Diabetic patients } \\
\hline & & & \multicolumn{2}{|c|}{ saliva } & \multicolumn{2}{|c|}{ urine } & \multicolumn{2}{|c|}{ saliva } & \multicolumn{2}{|c|}{ urine } \\
\hline & No. & $\%$ & No. & $\%$ & No. & $\%$ & No. & $\%$ & No. & $\%$ \\
\hline $\begin{array}{l}\text { Cryptococcus } \\
\text { neoformans }\end{array}$ & 1 & $1 \leqslant . r$ & 1 & $1 \leqslant .4$ & - & - & - & - & - & - \\
\hline $\begin{array}{l}\text { Cryptococcus } \\
\text { laurantii }\end{array}$ & $\varepsilon$ & ov.1 & r & rA.O & 1 & $1 \leqslant . \Gamma$ & 1 & $1 \leqslant . \mu$ & - & - \\
\hline $\begin{array}{l}\text { Saccharomyces } \\
\text { cereviciae }\end{array}$ & 1 & $1 \leq . r$ & 1 & $1 \leq . r$ & - & - & - & - & - & - \\
\hline $\begin{array}{l}\text { Rhodotorula } \\
\text { rubra }\end{array}$ & 1 & $1 \leq . r$ & 1 & $1 \leq . r$ & - & - & - & - & - & - \\
\hline Total & $\checkmark$ & $1 \ldots$ & 0 & $V I . \Sigma$ & 1 & $1 \leq . r$ & 1 & $1 \leqslant . \mu$ & - & - \\
\hline
\end{tabular}

Table $r$. Number of sensitive and resistant unusual yeasts isolated from saliva and urine of patients to the antifungal agents.

\begin{tabular}{|c|c|c|c|c|c|c|c|c|c|c|c|c|c|}
\hline \multirow{3}{*}{ Isolates } & \multirow{3}{*}{$\begin{array}{l}\text { Total } \\
\text { No. }\end{array}$} & \multicolumn{4}{|c|}{ Polyenes group } & \multicolumn{8}{|c|}{ Azoles compound } \\
\hline & & \multicolumn{2}{|c|}{ 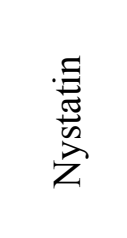 } & \multicolumn{2}{|c|}{ 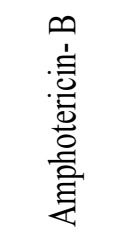 } & \multicolumn{2}{|c|}{ 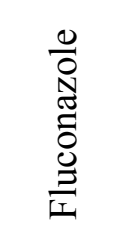 } & \multicolumn{2}{|c|}{ 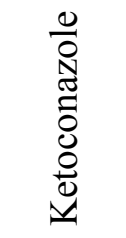 } & \multicolumn{2}{|c|}{ 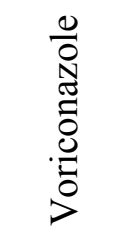 } & \multicolumn{2}{|c|}{ 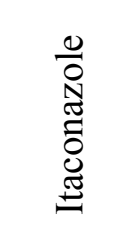 } \\
\hline & & $\mathrm{S}$ & $\mathrm{R}$ & $\mathrm{S}$ & $\mathrm{R}$ & $\mathrm{S}$ & $\mathrm{R}$ & $\mathrm{S}$ & $\mathrm{R}$ & $\mathrm{S}$ & $\mathrm{R}$ & $\mathrm{S}$ & $\mathrm{R}$ \\
\hline $\begin{array}{l}\text { Cryptococcus } \\
\text { neoformans }\end{array}$ & 1 & 1 & . & - & 1 & 1 & . & 1 & . & - & 1 & . & 1 \\
\hline $\begin{array}{l}\text { Cryptococcus } \\
\text { laurantii }\end{array}$ & $\varepsilon *$ & r & 1 & r & 1 & 1 & r & $\varepsilon$ & - & r & r & . & $\varepsilon$ \\
\hline $\begin{array}{l}\text { Saccharomyces } \\
\text { cereviciae }\end{array}$ & 1 & 1 & . & 1 & - & 1 & . & 1 & . & 1 & . & . & 1 \\
\hline $\begin{array}{l}\text { Rhodotorula } \\
\text { rubra }\end{array}$ & 1 & . & 1 & - & 1 & . & 1 & 1 & - & 1 & - & . & 1 \\
\hline Total & V & $\varepsilon$ & r & $\varepsilon$ & $r$ & $r$ & $\varepsilon$ & $V$ & $\cdot$ & $\varepsilon$ & $r$ & $\cdot$ & $V$ \\
\hline
\end{tabular}

$\mathrm{S}=$ Sensitive; $\mathrm{R}=$ Resistant

*One isolate of Cryptococcus laurantii from cancer patients in urine showed sensitivity to amphotericin B and ketoconazole. Sensitivity to nystatin was excluded for this species. 


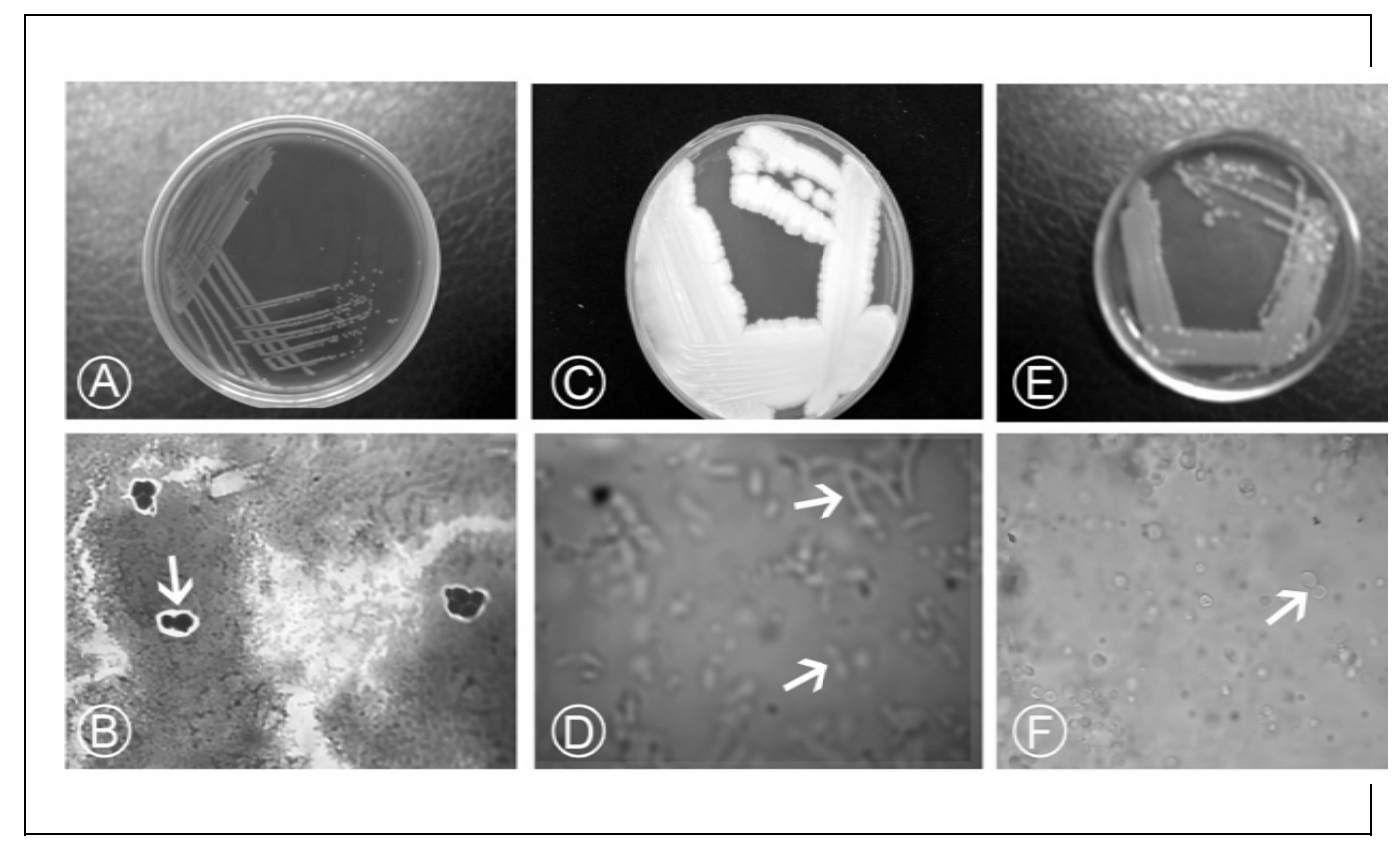

Fig. I unusual yeasts:

A- Cryptococcus neoformans on B.H.I blood agar showing yellowish brown mucoid colonies after ${ }^{\circ}$ days of incubation at ${ }^{\top} \mathrm{v}^{\circ} \mathrm{C}$.

B-Capsule stain for $C$. neoformans from culture showing the capsules around the budding yeast cells (arrowed).

C-Saccharomyces cereviciae on Sabouraud's agar showing white, dry colonies after ${ }^{r}$ days of incubation at $\mathrm{r}^{\circ} \mathrm{C}$.

D-Lactophenol mount of S.cereviciae showing budding yeast cells with short pseudohyphae (arrowed).

E-Rhodotorula rubra on Sabouraud's agar showing pink mucoid colonies after $r$ day of incubation at $\mathrm{r}^{\circ} \mathrm{C}$.

F-Lactophenol mount of $R$. rubra showing large budding yeast cells (arrowed).

\section{Discussion}

The opportunistic unusual yeasts that are sometime found on the skin, in urine, sputum, and in the digestive tract of healthy individuals may be responsible for deep infections, as well as for cutaneous mucosal diseases. Such deep infections are facilitated by immunosuppression, or by factors that enable these organisms to proliferate in different sites of the body and to penetrate deep in tissues'.

The identification of the isolated yeasts in the present study depended on the colonial morphology, microscopic examination and biochemical tests. Winn and Coworkers ( $(\ldots \top)$ mentioned that most fungal identification are based primarily on the assessment of colony morphology and microscopic features, but key biochemical tests may be required to differentiate between genera and species within a given group.

\section{The isolates}

Cryptococcus: two species in this genus were identified. Cryptococcus neoformans was isolated from saliva of cancer patient. Karkowska-Kuleta and 
Coworkers $(r \ldots q)$ reported that $C$. neoformans is less known that Candida spp., but now a day the morbidity and mortality caused by cryptococcosis is a significant problem. Other investigators reported that $C$. neoformans is a fungus that cause disease in people with immunodeficiencies associated with cancer related chemotherapy ${ }^{\prime r}$. This species was isolated and identified previously in our locality by the conventional method's and API- '- C system $^{\circ}$. The second species was $C$. laurantii which isolated from $\Sigma$ clinical specimens, and identified by API-r. C system for the first time. It should be noted that in a recent study comparing efficacy of detection by API- $r$. C system in clinical laboratory, seven of seven C. laurantii isolates were correctly identified by using the API$r$. C system ${ }^{r}$. Moreover, identification of Cryptococcal organisms based on solely upon phenological characteristics may result in mis-identification of Cryptocaccal species. Different authors mentioned that $C$. laurantii is only rarely isolated clinically, but it has recently been implicated in many cases among immunocompromised individuals ${ }^{\prime 2}$, and as a non-neoformans Cryptococcal spp. may be considered an emerging infective species ${ }^{\text {'^ }}$.

Saccharomyces:. One isolate of $S$. cereviciae was detected during the study from saliva of cancer patient. Saccharomyces spp. are now among emerging causative agents of opportunistic mycoses in patients who are immunocompromised due to various reasons $^{19}$. Enache-Angoulvant and Hennequin $(Y \ldots 0)$ mentioned that Saccharomyces organisms are increasingly reported as agents of invasive infection especially in immunosuppressed or critically ill patients, and the rate of carriage varies according to the population investigated.

Rhodotorula: This genus contain several spp. that may be present on the skin and in the sputum, urine and feces, and have been implicated as an infrequent cause of infection ${ }^{r}$. The main spp. is $R$. rubra ${ }^{r}$. One isolate of $R$. rubra from saliva of cancer patient was identified in the present study. It was reported that the risk factor for infection include underlying immunosuppression $^{r r}$. Other investigators mentioned that most infections caused by Rhodotorula spp. have been associated with patients who have solid tumor, diabetes, endocarditis and AIDS ${ }^{r}$.

\section{Susceptibility to antifungal agents}

The antibiogram of the unusual yeasts range from resistant to the most recent azole and amphotericin B to those are highly susceptible to all antifungal agents'. The in vitro susceptibility profile of $\mathrm{V}$ isolates of uncommon yeast that were detected in the clinical specimens was studied against $T$ antifungal agents. The susceptibility of the isolates within genus Cryptococcus was varies. Cryptococcus neoformans showed susceptibility to nystatin, fluconazole and ketoconazole. The \& isolates of $C$. laurantii varied in their sensitivity, $r$ of them were susceptible to amphotericin $\mathrm{B}$, while $r$ to voriconazole and one to fluconazole. Moreover, all the isolate were resistant to itraconazole but sensitive to ketoconazole. The one isolate from urine was excluded from the test of sensitivity to nystatin. Averbuch et al. $^{r}$ found that non-neoformans Cryptococcus spp. are susceptible to amphotericin B and various azole. However, some isolates of $C$. laurantii were found to be resistant to fluconazole. Moreover, BernalMortinez et $\mathrm{al}^{\text {rs }}$ reported that amphotericin B was in vitro the most active compound against all non- 
neoformans spp., fluconazole exhibit a limited activity, particularly against $C$. laurantii, while voriconazole and Itraconazole were active against most isolates but a significant rates of decreased susceptibility was noted.

The one isolate of $R$. rubra showed susceptibility to ketoconazole and voriconazole only. The wide spread antifungal prophylaxis with triazole antifungal agents mainly fluconazole in immunocompromised patients may allow the emergence of more resistant yeasts such as Rhodotorula spp ${ }^{r}$.

Saccharomyces cereviciae which detected from one clinical specimen showed sensitivity to all the antifungal agents except itraconazole. Different reports mentioned that the majority of serious infections due to Saccharomyces have been treated with amphotericin B. Moreover, ketoconazole, fluconazole and voriconazole exhibit good efficacy against $S$. cereviciae ${ }^{r}$.

In conclusion, unusual fungi are important cause of opportunistic infections in immunocompromised patients. All the isolated fungi were sensitive to ketoconazole but resistant to itraconazole with various sensitivity to other antifungal agents.

\section{References}

l. El-Tahawy ATA, Khalaf RMF. Rhodotorula rubra fungemia in an immunocompromised patient. Ann Saudi Med 1999;19(7):0rr_o.

r. Samonis G, Anatoliotaki M, Apostolakou H, et al. Transient fungemia due to Rhodotorula rubra in cancer patient: case report and review of the literature. Infection r... ; rq:IVr-r.

r. Lunardi LW, Aquino VR, Zimerman RA, Goldani LZ. Epidemiology and outcomes of Rhodotorula fungemia in a tertiary care hospital. Clin Infect Dis r... $; \leqslant$ \& $: \mathrm{e}^{T \cdot-r}$.
ร. Clombo AL, Dantas LS, Abramczyk ML, et al. Rhodotorula glutinis fungemia: a case report and literature. Braz J Infect Dis $199 V_{;} \mid(\varepsilon): r \cdot \varepsilon_{-} V^{\prime}$.

๑. Winn WC, Allen SD, Janda WM, et al. Koneman's color atlas and text book of diagnostic microbiology. th $^{\text {th }}$ ed. Lippincott Williams and Wilkins, Philadelphia chapter $r 1, r \ldots r ; 1 r 19-r r$.

7. Murray PR, Rosenthal KS, Pfaller MA. Medical microbiology. $0^{\text {th }} \mathrm{ed}$. Elsevier Mosby. Philadelphia Section $7, Y \cdots 0 ; \vee \wedge Y_{-} \wedge V$.

$\checkmark$. Henry S, D'Hondt L, Andre M, et al. Sacchromyces cerevisiae fungemia in a head and neck cancer patients: a case report and review of the literature. Acta Clin Belg $r \cdot . \varepsilon ; 09(\varepsilon): r r \cdot-r$.

^. Pien FD, Thompson RL, Deye D, Roberts GD. Rhodotorula septicemia: two cases and a review of the literature. Mayo Clin Proc $191 \cdot ; 00:$ YON_A.

१. $\mathrm{Wu}$ T, Samaranayake $\mathrm{P}$. The expression of secreted aspartyl proteinases of Candida species in human whole saliva. J Med Microbiol $1999 ;\{\Lambda: \vee / 1-r \cdot$

1. Kown-Chung KJ, Bennett JE. Medical Mycology. Lea and Febiger, Philadelphia, London. Chapter $1 \%, 1994 ; \% \cdot 0_{-} .9$.

11. Vale-Silva LA, Buchta V. Antifungal susceptibility testing by flow cytometry: is it the future ?. Mycoses $r \ldots r ;\{9: Y \uparrow)-V r$.

IY. Karkowska-Kuleta J, Rapala-Kozik M, Kozik A. Fungi pathogenic to humans: molecular bases of virulence of Candida albicans, Cryptococcus neoformans and Aspergillus fumigatus. Acta Biochimica Polonica Y..9;07:Y Yl. rs.

1T. Vartivarian SE, Anaissie EJ, Bodey JP. Emerging pathogens in immunocompromised patients: 
classification, diagnosis, and management. Clin Infect Dis 199r; $\mid v_{:} \leqslant \lambda v_{-} \leqslant 91$.

1 ร. AL-Dubooni HM. Epidemioclinical studies of Cryptococcus neoformans in Mosul and vicinity. M Sc thesis University of Mosul College of Medicine ( $19 \vee 9$ ).

10. Yehia MM. Identification of fungi in lower respiratory tract infection among immunocompetent and immunocompromised patients. Ph.D thesis University of Mosul College of Medicine ( $Y \cdots q)$.

17. FilionT, Kidd S, Aguirre K. Isolation of Cryptococcus laurantii from Canada Goose guano in rural upstate New York. Mycopathologia

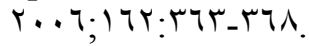

IV. Kordossis T, Avlami A, Velegraki A, et al. First report of Cryptococcus laurantii meningitis and a fatal case of Cryptococcus albidus Cryptococcaemia in AIDS patients J Med Mycol 1997;rч:rro rrq.

1^. Rosco DE . A survey to estimate the prevalence of Salmonella sp., Shigella sp., Yersinia sp. Bacteria and Cryptosporidia sp., Giardia sp. Protozoa in resident Canada Geese (Branta Canadensis) in New Jersey,,$\cdots$. . www.state.nj.us/dep/fgw/r.. 1/goo serpt.

19. Ponton JR, Ruchel KV, Clemons $\mathrm{DC}$, Coleman R, et al. Emerging pathogens. Med Mycol r...; r^: YTO_YYA.

$r \cdot$ Enache-Angoulvant A, Hennequin C. Invasive Saccharomyces infection: A comprehensive review. Clin Infect Dis Y..0; $\leqslant 1(11): 1009$ 71.

r). Anaissie E, Bodey GP, Kantarijian $\mathrm{H}$, et al. New spectrum of fungal infections in patients with cancer. Rev Infect Dis 1919;11: r $79 \_\vee \wedge$.

rr. LoRe V, Fishman NO, Nachamkin I. Recurrent catheter -related Rhodotorula rubra infection. Clin Microbiol Infect $r \ldots r ; q: \wedge q \vee-q \ldots$.

$r$. Averbuch D, Boekhoutt T, Falk R, et al. Fungemia in a cancer patient caused by fluconazole -resistant Cryptococcus laurantii. Med Mycol $r_{-} \cdot r_{;} \varepsilon \cdot: \varepsilon \vee q_{-} \wedge \varepsilon$.

$r \varepsilon$. Bernal-Martinez L, Gomez-Lopez A, Castelli MV, Mesa-Arango AC et al. susceptibility profile of clinical isolates of non Cryptococcus neoformans/nonCryptococcus gattii Cryptococus species and literature review. Med Mycol Y.1.; $\{\wedge(1): 9 \cdot-7$. 